\title{
A Reconnoitre of The Fascination with Psychosis in Literature and
}

\section{Film - A Study in Archetypes}

\section{Ms Sanjana Kundaliya}

PhD Research Scholar

Department of English

PSG College of Arts \& Science

Coimbatore, Tamil Nadu, India

sanjana.kundaliya@gmail.com

Dr M S Saritha

Assistant Professor

Department of English

PSG College of Arts \& Science

Coimbatore, Tamil Nadu, India

sarithathirugnanam@gmail.com

\section{Abstract}

Literature and art in all their forms have done well in representing man's mental disorders and afflictions in various ways, consecutively resulting in educating its consumers, moving its connoisseurs and inspiring future authors. "Psychosis" is a mental disorder, wherein reality is distorted, and "madness" denotes insanity, dementia; rash or irrational conduct. In this paper, these terms will be treated as such but, with an essential connotation toward heroism and eccentricity- both of which are character attributes that are of typical intrigue to readers. The aim of this study is to recognize, explore and expose the presence of a certain kind of 
fascination that the characters in literature and films embodying or representing certain kinds of madness have upon individuals. Recently, Todd Phillips's Joker (2019), a movie featuring mental illness witnessed an extraordinary box-office turnout. Upon examination, it can be established that this appeal or inclination towards eccentric characters bordering on madness is not a recent phenomenon but an ongoing trend since the Greek plays of Euripides (c.315 BC) and Seneca, the younger (1 BC). The theory of Archetypes is employed to streamline the recurrence of characters embodying psychosis, and have an appeal among the targeted consumers.

Keywords: Psychosis, Madness, Archetype, Collective Unconscious, Duality

\title{
1. Introduction
}

\author{
Much madness is divinest sense \\ To a discerning eye; \\ Much sense the starkest madness. \\ (Emily Dickinson, 'Much Madness is Divinest Sense')
}

In ancient Greece, renowned philosopher and the pioneer of Literary Criticism, Plato, in book 10 of his famous Republic banished all poets from his ideal republic. His verdict was primarily based on the conception that first, art is mimetic (thrice removed from reality) and therefore, deviates from the truth, and second, that poets breed immorality and emotional incompetence. The former argument is based on metaphysical grounds while the latter on ethical grounds. For the sake of this discussion, we consider the latter i.e., Plato's ethical concerns regarding imitative art. For Plato, the study of morals was basic and he therefore, wanted all art to be governed by morals and logic, not passion. His arguments have resurfaced 
many times throughout history and have subsequently been defended by critics and artists alike, the most famous being Aristotle and Philip Sidney in his An Apology for Poetrie (1595). His ethical argument, that poetry and art elicit immoral reactions from men and cause them to act irrationally, can largely be applied even today - regardless of the linguistic, national or cultural affiliation of the work of art or literature in question. However, straying from the tendency of quoting, rephrasing and hence, echoing the very same, long-standing Aristotelian counterarguments we attempt to merely conceive another.

Since their origin, poems, plays and later, novels and films have produced works that depict characters and project themes that may inherently be considered endemic to our subconscious appeal. Therefore, instead of supposing that art breeds emotional incontinence, it may be viable and more prudent to assume that it is the other way around - that it is in fact, man's and therefore, the artist's and subsequently the consumer's emotional incontinence that produces literary works and films and other forms of art depicting and projecting the themes and characteristics that are so abhorrent to Plato. However, the aim of this paper is not to prove or disprove Plato's premonition on morality but to merely point out that it is inherently the artists' and the readers' subconscious wish to have literary works that depict themes that induce profound emotions. Having said that, employing madness as a theme or as an embodiment by a character in a literary work, can be chosen for awareness and also, for generating empathy for those individuals afflicted with it in reality. Nevertheless, it may also be chosen as an attribute to facilitate eccentricity and the mystifying appeal of the character, as in the case of "Hamlet" in Hamlet and "Joker" in, The Dark Knight, 2008 film adaptation of the graphic story series by Christopher Nolan. 
2. Works Analysed for Archetypal Manifestation of the Purported Psychosis

The examples of literature and film mentioned in the preceding section exhibit the purported theory in this paper, that man has a certain fascination towards eccentric characters displaying certain mental follies or madness. Often, these character attributes have come to be associated with the "antiheroes". Moreover, an antihero who works outside of the moral confines of society because of his mental affliction set as a consequence of third-party influencer(s) or other traumatic antecedents which are not under his control, readily amasses more sympathy and fascination from the viewers. This can evidently be verified in a number of examples throughout the history of literature and Film. The prime examples of this in literature and film are the tragedies, Herakles $(416 B C)$ by Euripides, Hercules Furens $(c . A D$ 40-60) by Seneca the Younger, Hamlet (circa 1600) by William Shakespeare, and the novels Dr Jekyll and Mr Hyde (1886) by R. L. Stevenson and Shutter Island (2003) by Dennis Lehane, and the famous character of Joker in the films, The Dark Knight(2008) by Christopher Nolan and Joker(2019) by Todd Phillips.

\section{Methodology and Scope}

In order to trace the history of the manifestation of characters exhibiting madness that borders on eccentricity, and find a pattern in their conception, representation and reception, the Archetypal theory of criticism under the Swiss psychologist, Carl Jung will be employed. Particularly, the concept of 'archetypes' and the 'collective unconscious' in Jungian Psychology will shed light in understanding the connection shared by all individuals across time and space in their fascination with madness as a theme and character attribute in literature. Besides, this also raises concerns about what this fascination reveals about our society and us as individuals and devise further scope for studies pertaining to the present situation in regards 
with the increasing depression leading to mass-shootings and hiked suicide-rates especially in relatively rich countries and seemingly self-sufficient societies.

\section{A Precis of the Theory of Archetypes and Proposed Application}

Much of Archetypal theory of criticism originated from two other Academic disciplines, namely Sociological Anthropology and Psychoanalysis. By and large, Archetypal theory and criticism was developed and popularized in the works of the Canadian literary critic, Northrop Frye. Later, it acquired a different foot under the Swiss Psychologist, Carl Jung (1875-1961).

In its most basic sense, the purpose of Archetypal theory and criticism is to interpret and analyse texts by focusing on recurring myths and archetypes in narrative, symbols, images, themes and characters in literature. In Jungian Archetypal theory and Psychology, an 'archetype' may be the constantly recurring symbols in different forms of literature and art; it may also be the collectively inherited unconscious idea, image, pattern of thought, etc., that is universally present in individual psyches regardless of time, space and culture: 'Carl Jung ... used the term 'archetype' to refer to the experiences of our ancestors which get lodged in what he called 'the collective unconscious' of the whole race' (M S Nagarajan, 141).

From time to time, these archetypes may express themselves in art and literature of individual artists and writers from different places and cultures. Now, that the theory has been adequately explained to a sufficient degree, we may proceed to implement it to the major concern in this paper - 'Madness' in literature and film, and the fascination it induces among its consumers. Madness as an eccentric character attribute has been found in numerous characters in literary works throughout history and those works are still being studied or at least remembered to some degree. Consequently, we can presume that they have had a particular appeal among both critics and the masses. 
5. Tracing the Recurrence of Psychosis in Select Literary Works and Films

Psychosis or madness has been most adequately tapped in the popular novel, Shutter Island (2004) by the famous Edgar Award winning novelist and screenwriter, Dennis Lehane. Although, Lehane is known for writing novels focusing on crime, they usually contain twist endings, where the antagonist or the perpetrator of the conflict is revealed in an unexpected way. Among all his novels that feature the aforesaid scenario, Shutter Island creates a league of its own. The novel is an excellent model in its execution of what we call the 'false Protagonist' and the 'red herring' stratagem used in mystery novels. Shutter Island has also been adapted into a film of the same name under the direction of Martin Scorsese, one the most famous film directors in the contemporary period. Both the film and the novel, have amassed a cult-like fascination over time. It is the aspect of madness and Lehane's expert execution of it that has fascinated the readers.

The novel literally centres around the character of Andrew Laeddis alias Teddy Daniels, a former US Marshall and war hero. Andrew's mentally-ill wife, Rachel Solando kills their children. Out of grief, frustration and guilt for not getting his wife the help she needed, Andrew kills her. In order to cope with or rather forget his trauma, Andrew develops Dissociative Personality Disorder, creating an alter-ego - Teddy, through whose eyes we see the story unfold. Being highly intelligent and trained in combat Andrew becomes a liability to the Mental Asylum that he is being treated in. Eventually, after a series of violent episodes involving the security of the patients, guards and the doctors alike, it is decided that he be lobotomized. Andrew's doctor, Dr Cawley who is sympathetic to his patients, devises an elaborate two-days experiment to merge the two personalities of Andrew. One of the most intriguing and masterfully executed aspects in the novel, to the credit of Lehane is that the readers become accomplice to Andrew's mental delusion. Even at the end, when sufficient 
evidence corroborating Andrew's mental delusion is laid bare for the readers to see, many have not been able to come to terms with it.

Andrews's psychosis is an archetype stemming from the 'Collective Unconscious' of generations of dramatists, poets and novelist in the history of literature. His mental affliction can appositely be tallied with those of Hercules in Herakles and Hercules Furens and Dr Jekyll in A Strange Case of Dr Jekyll and Mr. Hyde. While the intrigue and sympathy that Andrew garners from the readers can be likened with that of Hamlet in Hamlet and Joker in The Dark Knight (2008) and Joker (2019).

There are various examples of the archetype of madness that can be traced throughout history in different forms of art and literature from around the world. To begin with, we have the Athenian tragedies, Herakles $(416 B C$ ) by Euripides, Hercules Furens (c. AD 40-60) by Seneca the Younger as mentioned earlier. In these two tragedies the titular character, a tragic hero, Herakles or Hercules has to overcome a set of obstacles to rescue his family - his father, Amphitryon, wife, Megara, and children from the underworld, where they have been held captive and sentenced to die. Despite being successful in rescuing his family, Hercules eventually kills them as he has been driven mad under the influence of Lyssa, the goddess of "Madness". In the play, 'madness' is personified, as in the case of Lyssa; and also, works as an essential character attribute, as in the case of Hercules, both of which prove to be the agents of conflict that bring about the tragic ending in the play.

The story of Hercules (fabula crepidata) has been recast many times; by Euripides in around c. 416 BC, and revived again by Seneca the Younger in 1 st Century BC, for instance. There is without doubt, a reason behind recasting plays and movies and even music these days from the past. These stories and ideas are seen as formulas that have worked in their own time. Therefore, the idea is to recreate them, as these works had an appeal when they appeared for the first time, and thus, they may have the same effect upon the next generation of consumers. 
The readers' likes and dislikes in a wide variety of subjects are inherently alike as they are part of the 'Collective Unconscious'. Therefore, the revival of the tragic story of Hercules by Euripides and its reception by the republic only explains the inclinations towards tragic plays, of which madness as a character attribute plays a major part.

Let us consider the similarities between Andrew in Shutter Island and Hercules in Herakles and Hercules Furens, for instance. Like Hercules, Andrew too is a warrior with heroic attributes; and just as Hercules kills his family, Andrew kills his wife. Hercules kills his family after having been driven mad, while Andrew is driven mad after killing his wife. Both involve psychosis and tragedy to a devastating effect. Like the Athenian tragedies discussed above, there are other examples of tragedies featuring psychosis, such as William Shakespeare's Hamlet, and German playwright, Johann Wolfgang Von Goethe's Faust Part One or Faust: A Tragedy (1808). In Faust Part One, the heroine Margarete (Gretchen) struggles with madness and guilt during which she drowns her own child. Faust Part One had a remarkable reception and is considered by many as the greatest work in German literature.

Shakespeare's Hamlet and its soliloquy "To be or not to be" is perhaps the most widely known and well-studied piece of English literature by critics, scholars, students and people from outside the literary sphere as well. It is one of the most popular tragedies in the world because of its captivating and suspenseful plot, riveting characters, memorable dialogues and soliloquies and the strangely eccentric Hamlet himself. Apart from this, the aspect of madness too gives Hamlet its fascinating charm: "I am but mad north-north-west. When the wind is/ southerly, I know a hawk from a handsaw.” (Hamlet II.ii.312-13)

Throughout the play, Hamlet constantly thinks about death - his own, and those of his enemies, especially Claudius, the murderer of his father. In present times, his obsession with suicide would be seen as a clear sign of depression. After suffering at the hands of his enemies, he becomes obsessed with revenge but prolongs it endlessly until he begins to collapse. On top 
of this, a part of his planning involves his feigning madness. "I perchance hereafter shall think meet/To put an antic disposition on" (Hamlet, I.V.)

Initially, Hamlet's antics seem to be part of his plans, however, as the play progresses, his behavior becomes more and more erratic and his dialogues are described as "wild and whirling" in the words of Horatio, who is in on Hamlet's plan of feigning madness. Hamlet has no reason to continue his "antic disposition" in the presence of his supporters, yet his actions say otherwise. Hence, it is this more than anything else, that informs our understanding that Hamlet is no longer pretending. He behaves exceedingly eccentric to a degree bordering on madness and it becomes impossible to ascertain if he is pretending or not. Perhaps, Shakespeare did not intend to distinguish Hamlet's madness between reality and pretense. This has led to a massive appeal and one of the most puzzling mysteries and debates in literary history among the audiences and critics alike.

It is believed that Shakespeare's idea of using Hamlet's madness as a ploy for furthering his revenge has been inspired by Hironimo's madness in Thomas Kyd's A Spanish tragedy. Despite this, Hamlet's mental disposition in the play has remained unclear until now. Nevertheless, it would not be far-fetched to take at face value that Hamlet had mental issues at least from today's standards. However, it is important to note that the presence of the themes of madness and the ghost in both Hamlet and A Spanish Tragedy does not qualify as an archetype, as the former is known to be inspired from the latter. It does however, support the idea purported in this paper that man has a fascination for mad and eccentric characters. In this regard, Andrew from Shutter Island can be seen as an archetype of Hamlet. Hamlet is clearly more of an antihero than a hero as his actions, a result of his mental disposition costs the lives those he loves. Likewise, it is difficult to specify whether Andrew is merely a trouble-maker in his asylum or possibly, a hero despite his insanity and delusion. Andrew's service in the war and during his time as a U S Marshal can be considered as an attribute of a hero. Moreover, 
Hamlet thinks about suicide several times throughout the play, which can be seen as a clear sign of mental illness. Yet, despite his mental affliction and the tragedy it brings, Hamlet is unanimously considered a tragic hero. Likewise, Andrew's desire for death is his form of punishment for not getting his wife help at the right time and killing her. Therefore, he too is comparable to a tragic hero despite his mental illness, his tragic flaw being his inability to let go of his past and find closure.

Apart from tragedies, as we move toward the eighteenth century, we witness the rise of short stories and novels, many of which feature mental illness. Since the rise of the novel, the depiction of mental illness found relative variety and freshness, as authors took liberty in exploring and experimenting with their characters and themes. The appearance of characters exhibiting mental illness of various sorts became even more substantial. However, we must be careful to distinguish between works containing elements or themes of madness or psychosis that induce fear and disgust in the minds of the readers, as opposed to those that elicit a certain kind of fascination from the readers. The former, can be part of a different topic of discussion for a separate study. In this paper, we focus on the latter, i.e., on fascination with psychosis. Novels such as William Godwin's Mandeville (1817) and Robert L. Stevenson's Strange Case of Dr Jekyll and Mr. Hyde (1886) portray their central characters with mental afflictions. Mandeville deals with the titular character's struggle with insanity, especially in the second and third volumes. As the story progresses it comes to be understood that Mandeville is an unreliable narrator. Therefore, much of its appeal comes from deducing what is real and what is not.

Apart from Mandeville, one of the other popular novels of the nineteenth century featuring mental illness is Stevenson's Strange Case of Dr Jekyll and Mr. Hyde. The novel was praised by the critics and loved by the masses, selling around forty thousand copies in the first six months of its publication, a huge number at the time. It has come to be so popular that the 
title of the novel "Jekyll and Hyde", has made its way into our vernacular as a phrase, popularly used to refer to people displaying erratic behavior or duality in their personality.

Stevenson's Strange Case of Dr Jekyll and Mr. Hyde deals with the character of Gabriel John Utterson, a London based lawyer investigating the strange and sinister occurrences involving the titular characters. However, as the story progresses, it is revealed that the titular characters are one and the same - Dr Henry Jekyll, a reputable doctor and Mr. Edward Hyde, his evil alter-ego. While in his persona of the doctor, Jekyll is shown to be amenable and kind, with an overall pleasant demeanor, described as a "large, well-made, smooth-faced man of fifty" (R L Stevenson, 44). Mr. Hyde on the other hand, who is initially understood to be a separate character appears to be the sinister and cunning villain trying to intimidate and hoodwink the good doctor. It is eventually revealed that Mr. Hyde is Dr Jekyll's evil alter-ego who is released with the help of a potion. Later in the novel, Mr. Hyde grows stronger and finally takes the dominant form, while Dr Jekyll the dormant, eventually disappearing completely.

Now, according to Stevenson, Dr Jekyll is not suffering from Dissociative Identity Disorder, and his affliction merely stems from evil itself. Therefore, what one understands from this is that Dr Jekyll's mental (and even, physical) condition stems from external factors, as in the case of Hercules in Herakles and Hercules Furens, when the tragic hero is influenced by the Goddess of “madness", Lyssa herself. If we consider Dr Jekyll's physical transformation into Mr. Hyde as the metaphorical representation of his evil self, i.e., his state when he is mentally ill and unstable then, by applying the theory of archetypes we can detect a pattern which is also present in the Athenian tragedies of Herakles and Hercules Furens, and Shakespeare's Hamlet and Lehane's Shutter Island. As discussed earlier, this a pattern of madness which generates erratic behavior or inexplicable actions from the characters; these actions however, are essentially a result of external influences - the agents of madness. These 
external influences are personified or given an identity of itself, as seen in the case of 'Lyssa' in Herakles and Evil, in the case of The Strange Case of Dr Jekyll and Mr. Hyde. Moreover, a similar case of mental affliction dealing with duality can be seen in Shutter Island as well. Therefore, a pattern or an archetype has been observed with the occurrences of madness in literature wherein, these occurrences may or may not be personified to be used as an external agent of 'madness' (or other mental afflictions) for influencing a character, or be simply used as an independent character. Consecutively, taking into consideration the Jungian theory of Archetypes, we can infer that Stevenson's ideas in the conception of Dr Jekyll alias Mr. Hyde stems from his being part of the 'Collective Unconscious' of our ancestors. Moreover, the book's and character's popularity too demonstrate the ongoing presence of our fascination with mental affliction especially if it adds to the character a sense of mystery or eccentricity or leads the story into a tragic ending.

Finally, moving the discussion towards psychosis in film. Since, its announcement, people from around the world had been anticipating the release of Todd Phillips's Joker (2019). The film has attempted to recast one of the most famous villains in pop culture today - 'Joker', of the DC Comic-book series, Batman. The character, though quite famous among nerds and the comic-book readers, did not quite have the same appeal until ten years ago. It was Christopher Nolan's The Dark Knight (2008) that cast the character of Joker not merely as a one-sided villain, but a character with many layers, blurred morals, and a unique perspective of our flawed modern world. Joker's 'psychosis' or his twisted and inverted way of looking at our society has awakened the viewers to a new vision. It is the vision that an 'antagonist' is not merely the diametrically opposite force used for propelling the protagonist's story to an end but, someone who can take his own place in that story - a protagonist in his own making. The Joker sees himself as the hero trying to bring an awakening, and in the process, influences quite 
a section of the audience into seeing the world through his eyes. This brought about a morning when society awoke to the vision that the world is more complex than it already was.

Joker (2019) has possibly had a far larger viewership than it would have been possible to ascertain, had Nolan's The Dark Knight not existed and thrived. Had Nolan's version of the Joker in The Dark Knight not released first, Todd Phillips's Joker may not have witnessed the turnout it received. The targeted viewership for this film has widened in the present day to include viewers that may not have necessarily even known about this film, let alone gone to see it. Nolan's presentation of the character of Joker in his The Dark Knight is an expression of the archetype of the mad characters stemming from the 'Collective Unconscious' of the authors discussed in this paper. For instance, Joker's mental disposition of seeing himself as a hero can be likened to Andrew's projection of his alter-ego, "the legendary Teddy Daniels" (Dennis Lehane, 14) on a quest to avenge his wife and uncover a huge conspiracy; as a result, both leave destruction in their wake.

Many authors intend to change perspectives of communities, as literature and art are known to start trends and at times, even bring about revolutions. What is learnt from the reception of Joker, is that society today openly embraces madness instead of flinching away from it. While Dennis Lehane, like Shakespeare, knowingly intends to play with the readers' minds and create a sensation through confusion - an unending debate regarding the madness of Andrew Laeddis, much like Hamlet. It may never be known if the conclusion of Shutter Island is a ploy to lead the readers into believing that at times, they themselves are delusional to some degrees when their own happiness is at stake.

6. Conclusion

Deep within, man has a fear of falling into the jaws of insanity, should calamities befall him. It is the affection for the loved ones and life itself that man refrains and pulls away from such tendencies. Yet, its pull is such that at the end of the day, there is a tendency to experience 
this madness through art and literature even when it comes appended with tragedy and grief. But again, it is known that Tragedy is cathartic and therefore, good for man.

Secondly, there is the aspect of man being a social being from the beginning. But, in his attempts at conforming to social norms, maintaining normalcy and ultimately uniformity, he loses his individuality. The fact that man has a desire to stand out cannot be disregarded. Films and literature provide an outlet for man to escape his mundane reality and release bottled up emotions. Therefore, in many ways literature and art serve as a form of therapy.

Finally, it is important to mention that the intent of this paper is not to undermine the originality, creativity and efforts of any of the authors discussed in this paper. Emergence of archetypes from time to time in the works of different authors and artists does not mean imitation. Presence of archetypal patterns merely point out the possibility of the existence of the wonderful prospect of a Collective Unconscious - that all of humanity around the world, from time past and time waiting, are mystically connected. 


\section{Works Cited}

Lehane, Dennis. Shutter Island. London: Transworld Publishers, 2003.

Nagarajan, M S. English Literary Criticism and Theory. Hyderabad: Orient Blackswan Private Limited, 2006.

Ruck, Carl. “DUALITY AND THE MADNESS OF HERAKLES.” Arethusa, vol. 9, no. 1, 1976, pp. 53-75. Available at :<JSTOR, www.jstor.org/stable/26307536. $>$ Date accessed: 22 Dec.

Shakespeare, William. The Tragedy of Hamlet, Prince of Denmark. New Folger's ed. New York: Washington Square Press/Pocket Books, 2003.

Stevenson, Robert Louis. The Strange Case of Dr. Jekyll and Mr. Hyde, second edition. ISBN 9781551116556. 2005. Available at : <https://books.google.co.in/books?id=Bi8wCEHnssQC\&pg=PA44\&lpg=PA44\&dq= $\underline{\text { with}+ \text { something }+ \text { of }+\mathrm{a}+\text { slyish }+ \text { cast } \& \text { redir_esc }=y \& h l=e n \# v=\text { onepage } \& q=\text { with } \% 20 \text { som }}$ ething\%20of\%20a\%20slyish\%20cast\&f=false $>$. Date accessed: 21 Dec. 